ID-177

\title{
Determination of Solid-State Sulfidation Mechanisms in Ion-Implanted Copper
}

J.C. Barbour, J.W. Braithwaite, and A.F. Wright, Sandia National Laboratories, Albuquerque, NM, 87185-1415 USA

\section{ABSTRACT}

Ion-beam irradiation and ion implantation were used to evaluate the influence of point defects and alloying elements on the sulfidation rate of copper films in atmospheric environments containing $\mathrm{H}_{2} \mathrm{~S}$. Low energy ions from an oxygen plasma were used to grow thin metal-oxide passivation layers on $\mathrm{Cu}$ films that were subsequently irradiated and exposed to sulfidizing environments $\left(50-600 \mathrm{ppb} \mathrm{H}_{2} \mathrm{~S}\right.$ in air with $0.5-85 \%$ relative humidity). The type of oxide proved to be important in that a $\mathrm{CuO}$ layer essentially prevented sulfidation whereas a $\mathrm{Cu}_{2} \mathrm{O}$ layer permitted sulfidation. For the native copper oxide $\left(\mathrm{Cu}_{2} \mathrm{O}\right)$, denșity-functional theory modeling of $\mathrm{Cu}$ divacancy binding energies suggested that alloying with In or $\mathrm{Al}$ would cause vacancy trapping and possibly slow the rate of sulfidation. This finding was then experimentally verified for an In-implanted $\mathrm{Cu}$ film. A series of marker experiments using unalloyed $\mathrm{Cu}$ showed that sulfidation proceeds by solid-state transport of $\mathrm{Cu}$ from the substrate through the $\mathrm{Cu}_{2} \mathrm{~S}$ product layer.

PACS: 61.72.Ww, 61.80.Jh, 66.30.Lw, 71.15.Mb

Keywords: implantation, irradiation, corrosion mechanisms, copper sulfidation, densityfunctional theory

J.C. Barbour

Sandia National Laboratories

MS 1415, Org. 01112

Albuquerque, NM 87185-1415 USA

e-mail:jcbarbo@sandia.gov

fax: 1-505-844-1197

tel: $1-505-844-5517$ 


\section{DISCLAIMER}

This report was prepared as an account of work sponsored by an agency of the United States Government. Neither the United States Government nor any agency thereof, nor any of their employees, make any warranty, express or implied, or assumes any legal liability or responsibility for the accuracy, completeness, or usefulness of any information, apparatus, product, or process disclosed, or represents that its use would not infringe privately owned rights. Reference herein to any specific commercial product, process, or service by trade name, trademark, manufacturer, or otherwise does not necessarily constitute or imply its endorsement, recommendation, or favoring by the United States Government or any agency thereof. The views and opinions of authors expressed herein do not necessarily state or reflect those of the United States Government or any agency thereof. 


\section{DISCLAIMER}

Portions of this document may be illegible in electronic image products. Images are produced from the best available original document. 


\section{INTRODUCTION}

Ion implantation has been used in a number of previous corrosion studies but generally the focus has been to alloy the surface to vary the corrosion susceptibility for a given base metal (e.g. steels, $\mathrm{Al}$, Ti see [1]). Less work has involved the application of ion beam modification to determine mechanisms of corrosion [2]. The study described in this paper is the first to use ion beams specifically to determine the influence of solid-state transport processes on the characteristics of atmospheric copper sulfidation. Solid-state diffusion of vacancies in $\mathrm{Cu}_{2} \mathrm{Cu}_{2} \mathrm{O}$, $\mathrm{CuO}$, and $\mathrm{Cu}_{2} \mathrm{~S}$ may be important processes in determining the kinetics of $\mathrm{Cu}$ sulfidation. The findings from this study have been achieved by combining solid-state measurements of sulfidation kinetics with density-functional theory (DFT) modeling. In this latter activity, the local density approximation is used to model the energetics of vacancy diffusion and trapping in the various materials of interest. Specific topics addressed in this study include the role point defects and vacancy traps have on $\mathrm{Cu}$ diffusivity through the oxide and sulfide layers and the resultant relative rate of copper sulfidation. The effect of varying oxide type through ion irradiation was also examined. In this work, ion beams introduce both vacancies and alloying elements to permit the effects of sulfidation to be examined and compared with predicted behavior from the DFT calculations.

\section{EXPERIMENT}

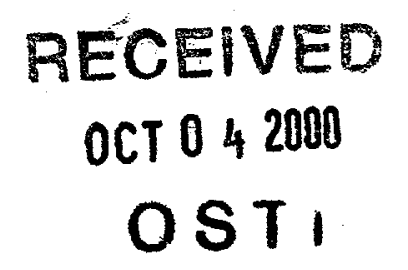

Copper films were electron beam evaporated at a rate of $0.15-0.3 \mathrm{~nm} / \mathrm{s}$ onto $\mathrm{SiO}_{2}$ coated Si wafers at $35-42^{\circ} \mathrm{C}$. The evaporation source material was 99.9999 at. $\% \mathrm{Cu}$. The base pressure of the sample preparation system was $2 \times 10^{-8}$ Torr. These samples were then oxidized by either using energetic $\mathrm{O}_{2}^{+}$ions from an electron cyclotron resonance (ECR) oxygen plasma at temperatures varying from $35^{\circ} \mathrm{C}$ to $60^{\circ} \mathrm{C}$ or by exposure to air at room temperature. The copper films exposed to an ECR plasma formed a thin, dense surface-oxide layer that could be ion 
irradiated with different ion species and fluences. The $\mathrm{O}_{2}{ }^{+}$ions in the ECR plasma, with a mean energy of approximately $30 \mathrm{eV}$, were generated using 100 Watts of $2.45 \mathrm{GHz}$ microwave power and a magnetic field of 875 Gauss, forming the ECR resonance condition upstream from the deposition chamber. The plasma offered a method to controllably form $\mathrm{CuO}$ at the surface, $\approx 4.0$ nm thick, in a clean UHV environment. The effects of ion irradiation on the ECR-oxidized layer were examined as a function of $200 \mathrm{keV} \mathrm{Cu}{ }^{+}$fluence. After ECR plasma oxidation, the sample surface was examined in-situ using X-ray Photoelectron Spectroscopy (XPS), stimulated with Al $\mathrm{K} \alpha \mathrm{X}$ Rays, in order to identify the type of oxide(s) present. The $\mathrm{Cu} 2 \mathrm{p}_{3 / 2}$ and $\mathrm{O} 1 \mathrm{~s}$ core level spectra were measured as well as the Cu LMM Auger spectrum.

The copper films were also implanted with different ion species to examine the effects of surface alloying on the sulfidation rate and specifically to look for changes in the rate due to vacancy trapping. Implanted species included D, O, and In. Samples were ion implanted with either In or $\mathrm{O}$ to form a uniform concentration profile of 0.5 at.\% up to a depth of $150 \mathrm{~nm}$. Another set of samples was implanted with $13 \mathrm{keV}$ D to form an implantation profile centered at a depth of $107 \mathrm{~nm}$ with a FWHM of $120 \mathrm{~nm}$. The ion implantation energies and fluences are given in Table I. The treated copper samples were sulfidized for various times in an ambient temperature atmosphere $\left(-23-25^{\circ} \mathrm{C}\right)$ containing $50-600 \mathrm{ppb} \mathrm{H}_{2} \mathrm{~S}, 0.5-80 \%$ relative humidity (RH), and air. Following exposure, the morphology and composition of the sulfide layer were examined using scanning electron microscopy and Rutherford backscattering spectrometry (RBS). The total thickness of the $\mathrm{Cu}_{2} \mathrm{~S}$ layer after $\mathrm{H}_{2} \mathrm{~S}$ exposure was measured using ion beam analysis of broad area samples.

\section{RESULTS AND DISCUSSION}


Figure 1 is the XPS spectrum for the $\mathrm{Cu} 2 \mathrm{p}_{3 / 2}$ region from a $\mathrm{Cu}$ film that was exposed to an ECR $\mathrm{O}_{2}$ plasma for 10 minutes at $50-60^{\circ} \mathrm{C}$ (solid line) and for the same sample after irradiation with $200 \mathrm{keV} \mathrm{Cu}$ ions to a fluence of $1.6 \times 10^{15} \mathrm{Cu} / \mathrm{cm}^{2}$. The spectrum for a similar sample that was oxidized in air for 4 days is also shown in this figure. The $\mathrm{Cu} 2 \mathrm{p}_{3 / 2}$ peak positions for $\mathrm{CuO}, \mathrm{Cu}$ and $\mathrm{Cu}_{2} \mathrm{O}$ are marked with arrows at the top of the figure. In addition, the broad shake-up peak (at 940 to $945 \mathrm{eV}$ ) is also indicated, which is a characteristic peak of $\mathrm{Cu}$ in the +2 oxidation state. Analysis of these spectra combined with the $\mathrm{O} 1 \mathrm{~s}$ and $\mathrm{Cu}$ LMM Auger transitions (not shown) demonstrated that the surface of the ECR oxidized sample is primarily composed of $\mathrm{CuO}$ [with possibly a small amount of $\mathrm{Cu}(\mathrm{OH})_{2}$ ] whereas the native air-oxide is $\mathrm{Cu}_{2} \mathrm{O}$ with a minor amount of $\mathrm{Cu}$ in a +2 oxidation state. Strikingly, the irradiated $\mathrm{CuO}$ surface was completely converted from a +2 oxidation state to $a+1$ state (no visible sign of a shake-up peak and a significant shift in the primary peak at $932.5 \mathrm{eV}$ ).

The structure of $\mathrm{Cu}_{2} \mathrm{O}$ is a fairly open, simple cubic structure with 2 formula units per cell. It has a density of $6.1 \mathrm{~g} / \mathrm{cm}^{3}$ and a molecular weight of $143.09 \mathrm{~g} /$ mole. In comparison, the structure of $\mathrm{CuO}$ is a more compact monoclinic crystal with 4 formula units per cell and a density of $6.51 \mathrm{~g} / \mathrm{cm}^{3}$, while having a molecular weight of only $79.55 \mathrm{~g} /$ mole. Thus, it is expected that the barrier for diffusion through the more compact $\mathrm{CuO}$ strúcture would be considerably higher.

A TRIM [3] calculation showed that the $\mathrm{Cu}$ ion average range $\left(\mathrm{R}_{\mathrm{p}}\right)$ is $58 \mathrm{~nm}$ (with a $\Delta \mathrm{R}_{\mathrm{p}}$ of $25 \mathrm{~nm})$ which is much greater than the thickness of the oxide $(\approx 4 \mathrm{~nm})$. Therefore, the compositional changes in the oxide layer from the tail of the $\mathrm{Cu}$ implant are expected to be minimal. However, the level of point defects for this fluence is high, increasing with depth in the oxide layer up to about 3 displacements per atom (dpa). Such a high level of defects causes a complete reduction in the oxidation state of $\mathrm{Cu}$ in the oxide from $\mathrm{Cu}^{++}$to $\mathrm{Cu}^{+}$. It is reasonable to 
assume that $\mathrm{Cu}$ would need to migrate in from the substrate to accommodate this complete change in the oxidation state. The existence of such a process would then require a high mobility of $\mathrm{Cu}$ into and through the highly defected oxide.

By comparing the sulfidation behavior of the $\mathrm{CuO} / \mathrm{Cu}$ to the $\mathrm{Cu}_{2} \mathrm{O} / \mathrm{Cu}$, a better understanding was obtained of the solid-state diffusion processes involved in the sulfidation of copper. Samples with oxidized surfaces that were completely $\mathrm{Cu}_{2} \mathrm{O}$ were compared to those with surfaces that were completely $\mathrm{CuO}$. After exposure for 5.5 hours at $24^{\circ} \mathrm{C}$ to a $65 \%$ relative humidity air atmosphere containing $600 \mathrm{ppb}_{2} \mathrm{~S}$, the $\mathrm{CuO}$-covered sample showed no visible (or measurable by ion beam analysis) sign of sulfidation whereas the sample with a $\mathrm{Cu}_{2} \mathrm{O}$ layer formed a $\mathrm{Cu}_{2} \mathrm{~S}$ layer $\approx 32 \mathrm{~nm}$ thick (Figure 2, RBS spectrum).

Modeling calculations were performed to determine the single-site $\mathrm{Cu}$-vacancy formation energy and the split-vacancy formation energy in $\mathrm{Cu}_{2} \mathrm{O}$. These calculations employed the Vienna Ab Initio Simulation Package (VASP) [4] and utilized ultrasoft pseudo-potentials [5] within the framework of the Kohn-Sham formulation of density-functional theory [6]. The split vacancy is one formed when a $\mathrm{Cu}$ atom is removed from the $\mathrm{Cu}$ sub-lattice and the crystal is allowed to relax to an equilibrium state (at $\mathrm{T}=0 \mathrm{~K}$ ) such that a neighboring $\mathrm{Cu}$ atom relaxes into an interstitial site (approximately half way toward the vacant site). The net result of this relaxation is to split the single vacancy between the two sites adjacent to the relaxed $\mathrm{Cu}$ in the interstitial site. The split-vacancy formation energy is approximately $0.10 \mathrm{eV}$ lower than the singlevacancy formation energy (depending slightly on the charge state of the vacancy). The barrier for Cu-vacancy diffusion through the split-vacancy site is $\approx 0.3 \mathrm{eV}$ whereas the barrier for diffusion through the single-vacancy site (no relaxation allowed) is $\approx 0.75 \mathrm{eV}$. In either case, the barrier for $\mathrm{Cu}$-vacancy through $\mathrm{Cu}_{2} \mathrm{O}$ is small suggesting that $\mathrm{Cu}$ should be relatively mobile in and through $\mathrm{Cu}_{2} \mathrm{O}$ (especially through the split-vacancy site). Transmission electron microscopy 
(TEM) of ECR-oxidized copper [7] revealed that the grain sizes for both $\mathrm{CuO}$ and $\mathrm{Cu}_{2} \mathrm{O}$ ranged from 10 to $100 \mathrm{~nm}$. Therefore, with such small but equivalent grain sizes for the two oxides, if copper sulfidation were primarily dependent upon grain boundary diffusion, then similar sulfidation rates should have been found for the $\mathrm{CuO}$ and $\mathrm{Cu}_{2} \mathrm{O}$ samples.

Combining the results from the DFT calculations, the TEM analysis, and the experimental results suggest that the sulfidation rate is slowed or completely suppressed by increasing the barrier to $\mathrm{Cu}$-vacancy diffusion. Another possible finding based on the experimental results is that if the sulfidation process depends on supplying copper to the surface, then lattice diffusion is as important if not more important than grain-boundary diffusion.

Further examination of the oxygen and sulfur signals in the RBS spectrum of Figure 2 indicates only two possible reaction processes for the formation of the $\mathrm{Cu}_{2} \mathrm{~S}$ layer on the surface. This spectrum was collected from a sample that was ECR-oxidized for $19 \mathrm{~min}$. at $75^{\circ} \mathrm{C}$, forming a $9.4 \mathrm{~nm}$ thick $\mathrm{CuO}$ layer. The sample was implanted with $200 \mathrm{keV} \mathrm{Cu}$ and sulfidized for 5.5 hours. (Further experimental details are given in the figure caption.) An enlarged view of the S signal (with background subtracted) and the $O$ signal are shown as insets in Figure 2. Arrows in these insets indicate the positions for the surface peaks of the $S$ and $O$, respectively. The sulfur clearly resides at the surface and extends in depth whereas the $\mathrm{O}$ signal is below the surface peak position demonstrating that the $\mathrm{O}$ is trapped below the surface $\mathrm{Cu}_{2} \mathrm{~S}$ layer. Either $\mathrm{Cu}$ vacancies have diffused through the oxide to form a surface sulfide layer, thereby burying the oxide layer, or the surface oxide layer reacted directly to form the sulfide, releasing the $\mathrm{O}$ and "snowplowing" it below the sulfidized layer. The latter possibility requires the diffusion of sulfur (or $\mathrm{S}$ vacancies) through the sulfide layer to supply the sulfidation reaction at the $\mathrm{Cu}_{2} \mathrm{O} / \mathrm{Cu}_{2} \mathrm{~S}$ interface.

A series of inert-marker experiments were performed to confirm which of the two candidate species actually diffuses through the combined oxide/sulfide layer. These experiments were performed using bulk polycrystalline $\mathrm{Cu}$ substrates possessing a native $\mathrm{Cu}_{2} \mathrm{O}$ surface. The 
samples were exposed for 4 hours at room temperature to a $80 \% \mathrm{RH}$ air environment containing $150 \mathrm{ppb} \mathrm{H}_{2} \mathrm{~S}$ that formed an initial $\mathrm{Cu}_{2} \mathrm{~S}$ layer approximately $135 \mathrm{~nm}$ thick. A Au marker layer was then deposited to a thickness equivalent to $2 \mathrm{~nm}$. However, for such a thin layer, the $\mathrm{Au}$ forms a low density of small patches (depicted schematically in Figure 3), each with a thickness greater than $2 \mathrm{~nm}$. The presence of this patchy Au layer was confirmed using a scanning electron microscope with backscattered electron imaging to highlight the elemental contrast between the $\mathrm{Au}$ and the $\mathrm{Cu}$. Many RBS spectra were collected as a function of sulfidation time, but for clarity, only 4 spectra are shown in this figure 3: (a) initial $4 \mathrm{hr}$. sulfidation with $\mathrm{Au}$ markers on top, (b) sample (a) + additional $4 \mathrm{hr}$. sulfidation, (c) sample (a) + additional $12 \mathrm{hr}$. sulfidation, and (d) sample (a) + additional $103 \mathrm{hr}$. sulfidation. The "motion" of the Au marker, to continually greater depths below the growing $\mathrm{Cu}_{2} \mathrm{~S}$ layer, clearly identifies $\mathrm{Cu}$ vacancies are the fastest moving species through the oxide and sulfide layers. A schematic diagram depicting the composition depth profile determined from spectrum (d) is shown inset in Figure 3. For each of the other spectra analyzed, the thickness of the layer $X_{0}$ was $135 \mathrm{~nm}$ that equaled the initial sulfide thickness before depositing the Au markers. Only for the final sulfidation did the layer $\mathrm{X}_{\mathrm{o}}$ begin to thicken slightly. This thickening corresponds to evidence in the gas flow analysis during the final sulfidation suggesting that the sulfide layer formed microcracks which permitted the sulfidizing species to reach the $\mathrm{Cu}$ substrate without diffusing through the solid state. The fact that the thickness of layer $X_{0}$ remained constant and all sulfide growth occurred above the markers for the other analyses proves that the sulfidizing species are not diffusing through the solid to react at the oxide/sulfide interface but rather the $\mathrm{Cu}$ vacancies are the primary moving species.

A preliminary finding of this study described earlier and based on a comparison of the relative sulfidation behavior of $\mathrm{CuO} / \mathrm{Cu}$ and $\mathrm{Cu}_{2} \mathrm{O} / \mathrm{Cu}$ samples was that the sulfidation rate can be slowed by increasing the barrier to Cu-vacancy diffusion. This concept was further tested 
using ion implantation to form surface alloys that could serve as Cu-vacancy traps and thereby slow the sulfidation rate. Again, DFT was employed to calculate the binding energy of a $\mathrm{Cu}$ divacancy to either an $\mathrm{Al}$ or In substitutional atom sitting on a $\mathrm{Cu}$ lattice site in $\mathrm{Cu}_{2} \mathrm{O}$. A divacancy trap was considered in order to maintain charge neutrality for the substitutionaldivacancy complex. The results of these calculations show strong trapping (binding) energies for both the $\mathrm{Al}$ and In substitutional atoms: $\left(\mathrm{Al}_{\mathrm{Cu}}+2 \mathrm{~V}_{\mathrm{Cu}}\right)^{\circ}=3.19 \mathrm{eV}$ with respect to unbound $\mathrm{Al}_{\mathrm{Cu}}{ }^{2+}$ and $2 \mathrm{~V}_{\mathrm{Cu}}{ }^{1-}$, and $\left(\operatorname{In}_{\mathrm{Cu}}+2 \mathrm{~V}_{\mathrm{Cu}}\right)^{\circ}=1.53 \mathrm{eV}$ with respect to unbound $\operatorname{In}_{\mathrm{Cu}}{ }^{2+}$ and $2 \mathrm{~V}_{\mathrm{Cu}}{ }^{1-}$. Thin film, ECR-oxidized $\mathrm{Cu}$ samples were implanted with $\mathrm{In}, \mathrm{O}$, and $\mathrm{D}$ according to the details shown in

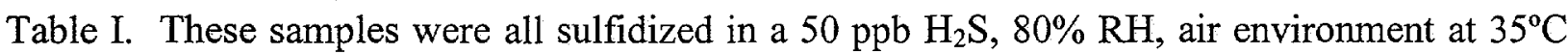
for 5 hours. The amount of sulfur uptake was measured using RBS with a $2.8 \mathrm{MeV} \mathrm{He}+$ beam incident normal to the sample surface and with a scattering angle of $164^{\circ}$. The sulfur signal for these samples is given Figure 4 with the background stripped-off: (a) In-implanted sample, (b) O-implanted sample, and (c) D-implanted sample. A control sample with only a native $\mathrm{Cu}_{2} \mathrm{O}$ on the surface gave a spectrum equivalent to the O-implanted sample and is not shown to maintain clarity in the figure. The surface peak position for sulfur is indicated in the figure with an arrow. These peaks are barely resolved and somewhat noisy as a result of the large $\mathrm{Cu}$ background signal subtracted from below them. Therefore, each signal was simply integrated to give the areal density of sulfur: (a) $3.6 \times 10^{16} \mathrm{~S} / \mathrm{cm}^{2} \pm 0.6 \times 10^{16} \mathrm{~S} / \mathrm{cm}^{2}$, (b) $4.8 \times 10^{16} \cdot \mathrm{S} \mathrm{cm}^{2} \pm 0.7 \times 10^{16}$ $\mathrm{S} / \mathrm{cm}^{2}$, and (c) $5.9 \times 10^{16} \mathrm{~S} / \mathrm{cm}^{2} \pm 0.8 \times 10^{16} \mathrm{~S} / \mathrm{cm}^{2}$. These results validate the ab initio calculation that the In is effective at slowing the sulfidation reaction, presumably by trapping vacancies, in comparison to the O-implanted sample and control sample. Further, the D implantation, which produced far less damage in the oxide layer than did the In implant, had a $65 \%$ greater sulfidation rate than did the In-implanted sample. This latter result suggests that the presence of hydrogen species in the $\mathrm{Cu}$ can either increase the $\mathrm{Cu}$-vacancy permeability or enhance the surface reaction rate. 


\section{SUMMARY}

Ion implantation and ion-beam irradiation has been used in this study for the first time to determine the influence of solid-state transport processes on the behavior of copper in atmospheric-sulfidizing environments. Processes involving diffusion in $\mathrm{Cu}, \mathrm{Cu}_{2} \mathrm{O}, \mathrm{CuO}$, and $\mathrm{Cu}_{2} \mathrm{~S}$ were considered. In combination with solid-state measurements of sulfidation kinetics and density-functional theory (DFT) calculations, several findings resulted including: (1) the role point defects and vacancy traps have on $\mathrm{Cu}$ diffusivity through the oxide and sulfide layers and the resultant effect on sulfidation kinetics, (2) the effect of the type of surface oxide, and (3) the identification of the dominant species that diffuses through the sulfide product layer. For the native copper oxide $\left(\mathrm{Cu}_{2} \mathrm{O}\right)$, the importance of vacancy trapping on slowing the rate of sulfidation was predicted and experimentally verified. The type of oxide proved to be important in that a $\mathrm{CuO}$ layer essentially prevents sulfidation whereas a $\mathrm{Cu}_{2} \mathrm{O}$ layer permits sulfidation. Finally, solid-state transport of $\mathrm{Cu}$ from the substrate through the $\mathrm{Cu}_{2} \mathrm{~S}$ product layer is the primary mass transport process.

\section{ACKNOWLEDGMENTS}

We thank Ken Minor for performing the ion implantation, Dan Buller for assistance with the ion beam analysis, and Sam Lucero for assistance with sulfidation exposures. Sandia is a multiprogram laboratory operated by Sandia Corporation, a Lockheed Martin Company, for the United States Department of Energy under Contract DE-AC04-94AL85000.

\section{REFERENCES}

[1] C. M. Rangel and T. I. C. Paiva, Surface and Coatings Tech. 83, (1996) 194; B. D. Sartwell, P. N. Natishan, E. P. Donovan, S. N. Bunker, and A. J. Armini, Surface and Coatings Tech. 83, 
(1996) 183; H. Schmidt, G. Stechmesser, J. Witte, and M. Soltani-Farshi, Corrosion Science 40, (1998) 1533.

[2] N. G. Thompson, B. D. Lichter, B. R. Apleton, E. J. Kelly, and C. W. White, in "Ion Implantation Metallurgy", edited by C. M. Preece and J. K. Hirvonen (The Metallurgical Society of AIME, Warrendale, PA, 1980) p. 181; G. Dearnely, in "Applications of Ion Beams to Metals", edited by S. T. Picraux, E. P. EerNisse, and F. L. Vook (Plenum Press, New York, 1974) p. 63. [3] J. F. Ziegler and J. P. Biersack, The Stopping and Range of Ions in Solids, (Pergamon, New York, 1985); see also TRIM92 computer code by J. F. Ziegler, IBM Yorktown Heights, New York.

[4] G. Kresse and J. Hafner, Phys. Rev. B 47 (1993), 558; 49, (1994) 14 251; G. Kresse and J. Furthmüller; Comput. Mater. Sci. 6, (1996) 15; Phys. Rev. B 54, (1996) 11169.

[5] D. Vanderbilt, Phys. Rev. B 41, (1990) 7892.

[6] W. Kohn and L. J. Sham, Phys. Rev. 140, (1965) A1133; D. M. Ceperley and B. J. Alder, Phys. Rev. Lett. 45, (1980) 566, J. P. Perdew and A. Zunger, Phys. Rev. B 23, (1981) 5048. [7] Michael Campin, New Mexico State University, private communication. 


\section{TABLES}

Table I. Ion Implantation Conditions for Examining Surface Alloying Effects on Sulfidation

\begin{tabular}{c|c|c|c}
$\begin{array}{c}\text { Species } \Rightarrow \\
\text { Implant \# } 3\end{array}$ & \multicolumn{1}{|c|}{$\mathrm{D}$} & \multicolumn{1}{|c|}{$\mathrm{O}$} & \multicolumn{1}{|c}{$\mathrm{In}$} \\
\hline 1 & $13 \mathrm{keV}$, & $95 \mathrm{keV}$, & $600 \mathrm{keV}$, \\
& $5.5 \times 10^{15} \mathrm{~cm}^{-2}$ & $5 \times 10^{15} \mathrm{~cm}^{-2}$ & $4 \times 10^{15} \mathrm{~cm}^{-2}$ \\
\hline 2 & & $45 \mathrm{keV}$, & $300 \mathrm{keV}$, \\
& & $1 \times 10^{15} \mathrm{~cm}^{-2}$ & $8 \times 10^{14} \mathrm{~cm}^{-2}$ \\
\hline 3 & & $20 \mathrm{keV}$, & $125 \mathrm{keV}^{14}$ \\
& & $8 \times 10^{14} \mathrm{~cm}^{-2}$ & $8 \times 10^{14} \mathrm{~cm}^{-2}$ \\
\hline 4 & & & $30 \mathrm{keV}^{1}$ \\
& & & $2.5 \times 10^{14} \mathrm{~cm}^{-2}$
\end{tabular}

\section{FIGURE CAPTIONS}

1. $\mathrm{Cu} 2 \mathrm{p}_{3 / 2}$ XPS spectrum taken using $\mathrm{Al} \mathrm{K} \alpha \mathrm{X}$-Rays for different $\mathrm{Cu}$-oxides: air-formed, $\mathrm{ECR}$ oxidized, and ECR-oxidized and irradiated with $200 \mathrm{keV} \mathrm{Cu}$ ions

2. RBS spectrum from an ECR-oxidized sample implanted with $200 \mathrm{keV} \mathrm{Cu}$ to a fluence of $1 \times 10^{15} \mathrm{Cu} / \mathrm{cm}^{2}$ and then sulfidized for 5.5 hours in a $65 \% \mathrm{RH}$ air environment containing 600 $\mathrm{ppb} \mathrm{H}_{2} \mathrm{~S}$. The RBS spectrum was collected using $2.8 \mathrm{MeV} \mathrm{He}$ ions incident at $45^{\circ}$ from the surface normal and a scattering angle of $164^{\circ}$.

3. RBS spectra collected from the marker-experiment samples using $2 \mathrm{MeV} \mathrm{He}^{+}$ions incident along the sample normal and a scattering angle of $164^{\circ}$. The Au patches, indicated schematically in the inset, were used as markers to determine the dominant moving species.

4. Sulfur signals determined from RBS analysis with a $2.8 \mathrm{MeV} \mathrm{He}+$ beam incident normal to the sample surface and with a scattering angle of $164^{\circ}:$ (a) In implanted, (b) $\mathrm{O}$ implanted, and (c) $\mathrm{D}$ implanted. The large $\mathrm{Cu}$ background signal was subtracted from below the $\mathrm{S}$ peak for each of these spectra. 


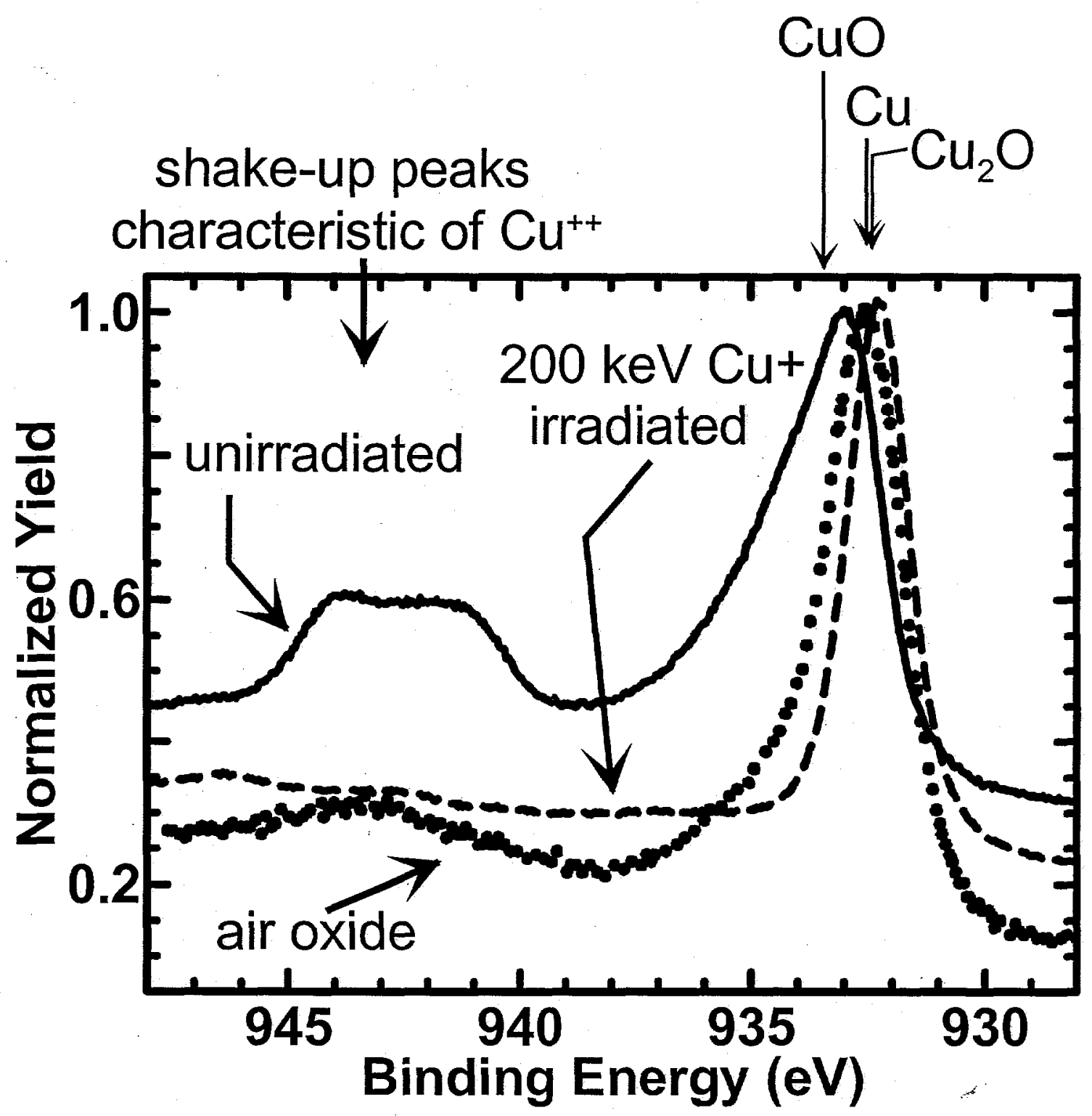

Fig. 1 


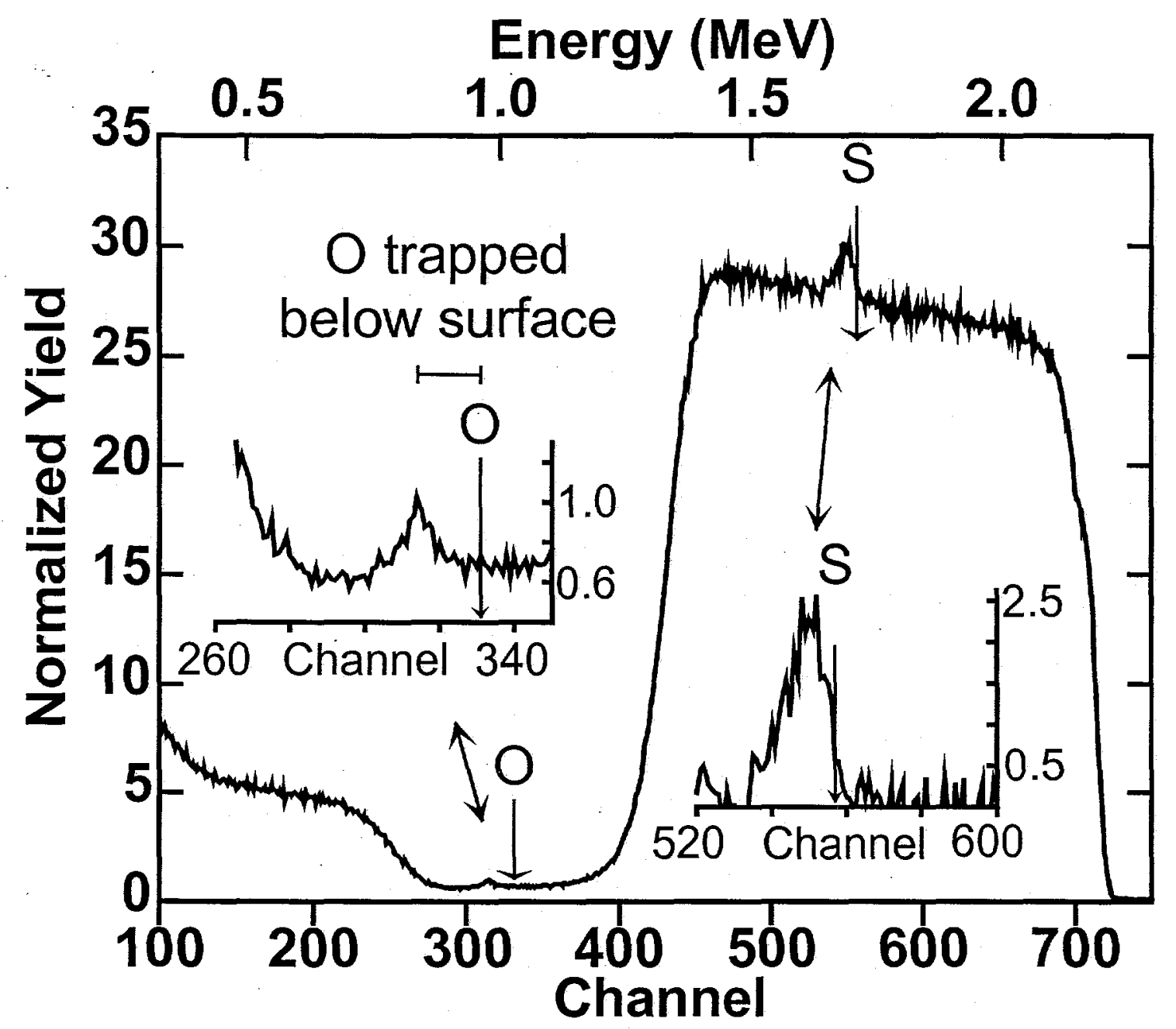

Fig. 2 


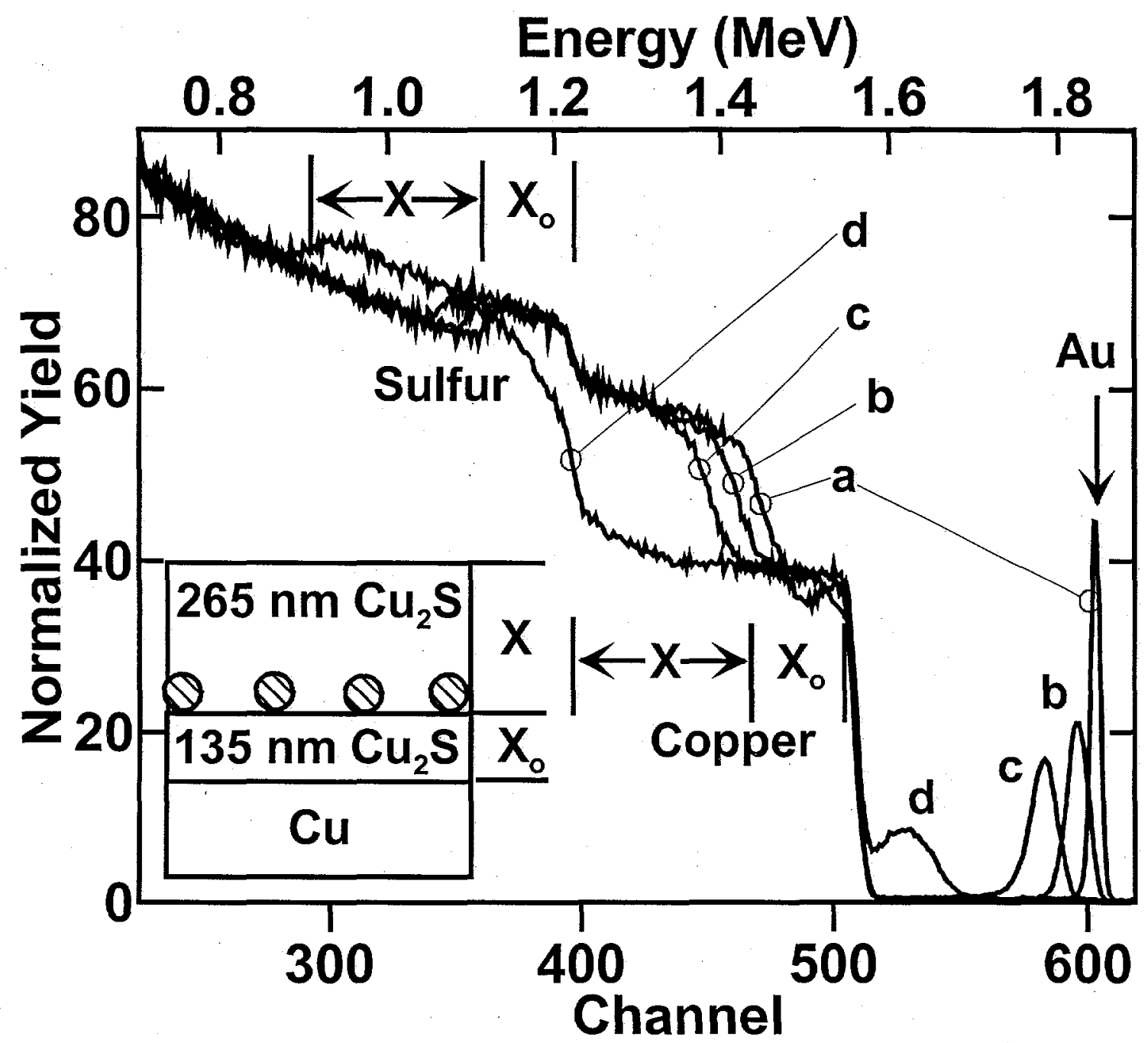

Fig. 3 


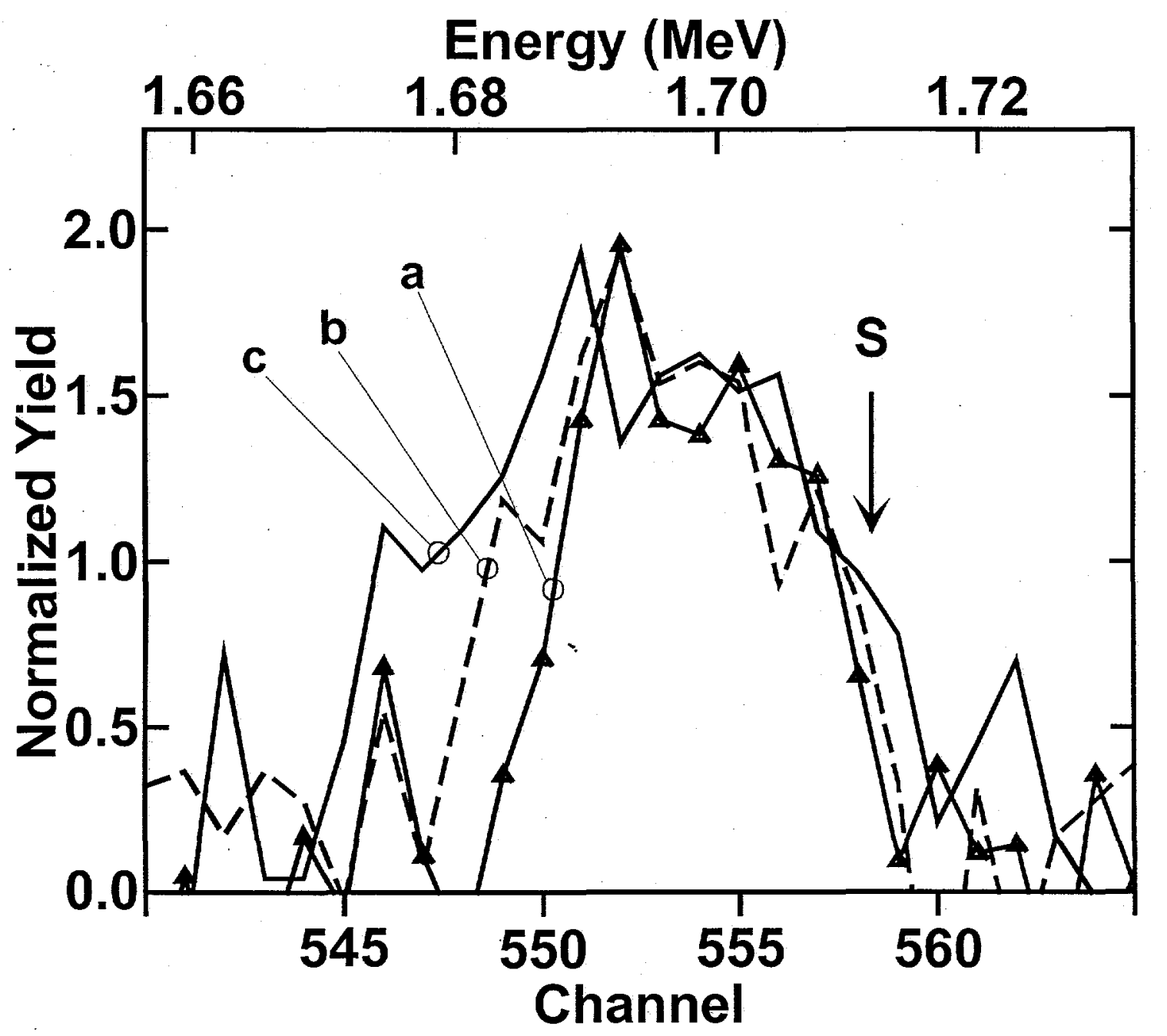

Fig. 4. 